\title{
LACRIMAL ABSCESS IN THE NEWBORN* A REPORT OF SEVEN CASES
}

\author{
BY
}

\author{
O. O. FFOOKS \\ Royal Infirmary, Sheffield
}

Although the treatment of congenital dacryostenosis has led to controversy for many years, its main complication, acute dacryocystitis with formation of lacrimal abscess, has received little attention.

Abscess formation in congenital dacryostenosis is rare, but is probably not as infrequent as reports in the literature suggest. Some cases of congenital lacrimal fistula are probably inflammatory in origin (Duke-Elder, 1952) and many cases of chronic dacryocystitis in children requiring surgical intervention probably originate from unsuccessful treatment of recurrent lacrimal abscess in infancy (Zentmayer, 1937; MacGillivray, 1939).

Mayou (1908) reported eight cases of lacrimal abscess in the newborn, and since that time isolated cases have been reported by Holdsworth (1913), Riser (1935), Town (1943), Cassady (1948), Redmond (1949), Koke (1950), Blankstein (1952), and Hurd (1955).

During the past 5 years, 440 cases of congenital dacryostenosis have been treated at the Children's Hospital, Sheffield. Seven of these patients presented with acute dacryocystitis with abscess formation.

Lacrimal abscess in the newborn does not arise de novo. There is always evidence of congenital dacryostenosis before the occurrence of acute inflammation of the lacrimal sac. There may be either discharge or epiphora occurring shortly after birth, or an encysted mucocoele may be present at birth.

Symptoms of acute inflammation usually occur within one month of birth, but cases of later onset have been reported ( 2 months, Riser, 1935; 4 months, Koke, 1950).

In the present series, acute symptoms occurred within one month of birth in all cases, and the infecting organism, where known, was $S$. pyogenes.

\section{Case Reports}

Case 1, a boy aged one month, was first seen on July 12,1955, with a left lacrimal abscess. A chronic discharge from his left eye had been noticed 4 days after birth. On July 9 his mother observed a swelling at the inner corner of the left eye which had become red and inflamed.

* Received for publication August 29, 1960. 
Treatment.-Systemic penicillin. The abscess did not settle and it was incised on July 15. The infection slowly resolved and the naso-lacrimal ducts were probed on July 25.

Result.-There has been no discharge or epiphora since.

Case 2, a boy aged 9 days, was first seen on December 7, 1956, with a right lacrimal abscess with purulent discharge. His mother had noticed a swelling in the region of the right inner canthus at birth. When he was 3 days old, the swelling became red and inflamed and was accompanied by a purulent discharge.

Treatment.-He was admitted to hospital and started on systemic penicillin and local antibiotics. On December 8 the abscess was pointing over the lacrimal sac, and the naso-lacrimal ducts were probed with release of a large quantity of pus. Rapid resolution of the abscess followed, and by December 10 all signs of inflammation had disappeared and there was no discharge.

Result.-There has since been no discharge or epiphora.

Case 3, a boy aged 5 days, was first seen on October 2, 1957, with a right lacrimal abscess. Both eyes were discharging and a swelling was present near the right inner canthus at birth, and 3 days later the swelling became red and inflamed.

Treatment.-He was admitted to hospital and started on systemic and local penicillin, and the inflammation settled without rupture of the abscess. On October 6 he appeared symptom-free and was discharged, but on October 14 the swelling of the right lacrimal sac recurred, with slight inflammation. The naso-lacrimal ducts were then probed.

Result.-There has since been no discharge or epiphora.

Case 4, a boy aged 1 month, was first seen on September 18, 1957, with a right lacrimal abscess. Epiphora from the right eye had been noted from one week of age, and 2 weeks later a swelling and inflammation had appeared near the right inner canthus.

Treatment.-The abscess was incised and systemic penicillin and local antibiotics given. The inflammation settled slowly and by October 16 he appeared symptom-free.

Result.-The child did not attend again, but his mother states that the eye has only watered once or twice during the past 3 years.

Case 5, a girl aged 1 month, was first seen on February 12 with a right lacrimal abscess with purulent discharge. There had been epiphora from the right eye since she was one week old; at 2 weeks of age the right eye started discharging, with gradual increase in redness and swelling near the inner canthus. She had been treated at home with local antibiotic drops, but the inflammation had become worse.

Treatment.- She was admitted to hospital and started on systemic penicillin. The naso-lacrimal duct was probed on February 13. Rapid resolution followed and all signs of inflammation had disappeared by February 16.

Result.-There has been no further trouble and both eyes have since been free of discharge and epiphora.

Case 6, a girl aged 1 month, was first seen on July 9, 1958, with an acute right dacryocystitis. She had had a discharge from both eyes since she was 3 days old. One day previously the right eye had become inflamed near the inner canthus.

Treatment.-She was treated with systemic penicillin daily; by July 14 the right eye had become more inflamed and swollen, and on July 16 a lacrimal abscess developed. 
She was admitted to hospital and the abscess was incised; this was followed by slow resolution. On July 24 bilateral probing was undertaken, both lacrimal sacs were large and full of pus, the naso-lacrimal ducts being blocked. Discharge continued from both eyes and further probing was unsuccessful. The baby was discharged from hospital on August 22. On October 9 she was re-admitted with a right lacrimal abscess, and lacrimal probes were passed successfully. On October 14 the right eye was symptom-free, with no discharge or epiphora.

Result.-The right eye has remained symptom-free, but the left tear duct still discharges.

Case 7, a boy aged 5 weeks, was first seen on April 15, 1960, with a right lacrimal abscess. He had had a discharge from the right eye since he was 2 days old. He developed an acute dacryocystitis when 5 days old and was treated with antibiotics. When he was 3 weeks old, a lacrimal abscess was incised and the inflammation settled. He was discharged from hospital one week later on April 8, but 3 days later marked inflammation returned.

Treatment.-He was admitted to hospital and started on systemic penicillin. The abscess slowly resolved and on April 21 both naso-lacrimal ducts were probed. By April 24 the right eye was quiet with no sign of inflammation.

Result.-The eye has been free of discharge and epiphora ever since.

\section{Discussion}

Conservative treatment of lacrimal abscess with systemic antibiotics and incision of the abscess when necessary is usually unsatisfactory. When this is done, recurrence of the abscess is common, a lacrimal fistula may occur, and after repeated incisions the naso-lacrimal duct becomes permanently blocked and a dacryocystorhinostomy is required (Redmond, 1949; Blankstein, 1952). If the abscess settles after incision, early probing may cure some cases (Riser, 1935; Koke, 1950) but surgical treatment may still be necessary (Blankstein, 1952).

Hurd (1955) advocated immediate probing of the lacrimal abscess and, as he says, "institution of normal drainage seems logical". The improvement in his two cases was immediate.

The results in the present series are summarized in the Table. Where probing was done as an initial procedure (Cases 2 and 5) or without incision of the abscess (Case 3), cure was rapid. Where the abscess was incised initially, one (Case 4) needed no further treatment and is now practically symptom-free, one (Case 1) was cured easily after probing, and two (Cases 6 and 7) were eventually cured after the abscess had recurred and a further probing performed.

\section{Conclusion}

It is suggested that acute dacryocystitis in infancy should be treated by early probing under cover of systemic antibiotics. Where this was done, resolution was rapid. The condition may clear up after incision of the abscess with antibiotic treatment alone, but recurrence is usual. Early 
TABLE

TREATMENT OF SEVEN CASES OF LACRIMAL ABSCESS IN INFANTS

\begin{tabular}{|c|c|c|c|c|c|c|}
\hline $\begin{array}{l}\text { Case } \\
\text { No. }\end{array}$ & Sex & $\begin{array}{l}\text { Age at } \\
\text { Onset }\end{array}$ & Culture & $\begin{array}{c}\text { Initial } \\
\text { Treatment } \\
\text { of Abscess }\end{array}$ & $\begin{array}{l}\text { Further } \\
\text { Treatment }\end{array}$ & Result \\
\hline 1 & $\mathbf{M}$ & $1 \mathrm{mth}$ & S. pyogenes & Incised & Probed 10 days later & Cured after probing \\
\hline 2 & $\mathbf{M}$ & 9 days & 一 & Probing & None & Cured in 2 days \\
\hline 3 & $\mathbf{M}$ & 5 days & - & $\begin{array}{l}\text { Conserva- } \\
\text { tive }\end{array}$ & $\begin{array}{l}\text { Probed after early } \\
\text { recurrence }\end{array}$ & $\begin{array}{l}\text { Cured immediately } \\
\text { after probing }\end{array}$ \\
\hline 4 & $\mathbf{M}$ & $1 \mathrm{mth}$ & S. pyogenes & Incised & None & $\begin{array}{l}\text { Very occasional } \\
\text { epiphora }\end{array}$ \\
\hline 5 & $\mathbf{F}$ & $1 \mathrm{mth}$ & - & Probing & None & Cured in 4 days \\
\hline 6 & $\mathbf{F}$ & $1 \mathrm{mth}$ & Sterile & Incised & $\begin{array}{l}\text { Probed twice unsuc- } \\
\text { cessfully } \\
\text { Abscess recurred } 3 \\
\text { wks later and was } \\
\text { probed again }\end{array}$ & $\begin{array}{l}\text { Cured after final } \\
\text { probing }\end{array}$ \\
\hline 7 & $\mathbf{M}$ & 3 wks & S. pyogenes & Incised & $\begin{array}{l}\text { Abscess recurred } \\
1 \text { week later } \\
\text { Probed }\end{array}$ & $\begin{array}{l}\text { Cured easily after } \\
\text { probing }\end{array}$ \\
\hline
\end{tabular}

probing after initial incision of the abscess cures some cases, but the condition may be very difficult to cure if infection is prolonged, and may even be impossible.

\section{Summary}

Seven cases of lacrimal abscess in infancy are reported and their treatment reviewed. Early probing is advocated.

My thanks are due to Mr. A. B. Nutt for permission to use his cases.

\section{REFERENCES}

Blankstein, S. S. (1952). A.M.A. Arch. Ophthal., 48, 322.

CASSADY, J. V. (1948). Arch. Ophthal. (Chicago), 39, 491.

DuKE-ELDER, S. (1952). "Text-book of Ophthalmology", vol. 5, p. 4712. Kimpton, London.

HoldswORTH, F. (1913). Ophthal. Rec. (Chicago), $22,544$.

HuRd, A. C. (1955). J. Maine med. Ass., 46, 12.

KOKE, M. P. (1950). Arch. Ophthal. (Chicago), 43, 750.

MacGillivray, A. M. (1939). Brit. J. Ophthal., 23, 630.

MAYOU, M. S. (1908). Roy. Lond. ophthal. Hosp. Rep., 17, 246.

ReDmoND, K. B. (1949). Med. J. Aust., 1, 462.

RISER, R. O. (1935). Amer.J. Ophthal., 18, 1116.

Town, A. E. (1943). Arch. Ophthal. (Chicago), 29, 767.

ZENTMAYER, W. (1937). Ibid., 17, 1152. 